\title{
Analytical study of hysterectomies
}

\section{Shivaji Neelgund*, Panchaksharayya Hiremath}

Department of Obstetrics and Gynaecology, Sri Venkateshwaraa Medical College Hospital and Research Centre, Ariyur, Puducherry, India

Received: 15 May 2016

Revised: 18 May 2016

Accepted: 11 June 2016

\section{*Correspondence:}

Dr. Shivaji Mallappa Neelgund,

E-mail: shivajineelgund5@gmail.com

Copyright: (C) the author(s), publisher and licensee Medip Academy. This is an open-access article distributed under the terms of the Creative Commons Attribution Non-Commercial License, which permits unrestricted non-commercial use, distribution, and reproduction in any medium, provided the original work is properly cited.

\section{ABSTRACT}

Background: Since early $20^{\text {th }}$ century hysterectomy came into widespread use. The incidence of hysterectomy varies from place to place depending upon the clinical and clinician factors. Sometimes there are considerable problems in clinical assessments as the patient's complaints, the clinical findings and per-operative diagnosis does not correlate with histopathological diagnosis. This is a retrospective study to correlate and evaluate the sensitivity between the indications, demographic features, clinical presentations, per-operative findings and histopathological diagnosis of patients who underwent hysterectomy.

Methods: This study was conducted in the department of obstetrics and gynaecology, in SVMCH and RC, Ariyur, Pondicherry, India. There were 1124 cases of hysterectomies done over a period of five years, from 2011 to 2015. Data was recorded and analyzed from the case record of each patient, which was obtained from the medical record department of the hospital.

Results: During the study period there were 1124 cases of hysterectomies done; out of which total abdominal hysterectomy with bilateral salphingo-oophorectomy were 915 cases $81.4 \%$. Leiomyoma is the dominant histopathological diagnosis in our study $22.4 \%$. Both adenomyosis and leiomyoma was present in $6.4 \%$ of the cases. In our study the pre-operative diagnosis, specificity to pathological correlation is 91 to $100 \%$, and for leiomyoma it is $99 \%$.

Conclusions: Hysterectomy is the preferred procedure in the treatment for pelvic pathologies like fibroid, adenomyosis, pelvic inflammatory disease and malignant disorder, and genital prolapse. Majority of the hysterectomy procedures are performed via an abdominal approach.

Keywords: Hysterectomy, Menorrhagia, Histopathology, Leiomyoma, Adenomyosis

\section{INTRODUCTION}

Since early $20^{\text {th }}$ century hysterectomy came into widespread use due to safety of anaesthesia, aseptic technique, antisepsis and new generation antibiotics which lead to the development of safe surgical treatments for benign and malignant gynaecologic disease. The mortality rate of hysterectomy decreased from $70 \%$ in 1880 to $3 \%$ in 1930 , at present it is less than 0.1 percent. $^{1}$
The incidence of hysterectomy varies from place to place depending upon the clinical and clinician factors. ${ }^{2}$ The Indian incidence is $6 \%$ to $8 \%$ and rising, whereas in developed countries it is (10-20\%). ${ }^{3}$ In 1507 Berengarius of Bologna preformed the first hysterectomy by vaginal route, though credit was given to Langen, in 1813. Clay in 1844 , performed the first total abdominal hysterectomy with bilateral salphingo-oophorectomy. ${ }^{4}$ 
There has been a remarkable improvement in conservative management of uterine lesions; still hysterectomy is the preferred procedure in the treatment for pelvic pathologies like leiomyoma, adenomyosis, pelvic inflammatory disease and malignant disorders. ${ }^{5}$ Also the increase in hysterectomies may be due to prophylaxis against uterine cancer, in cases of mild genital prolapse and premenopausal menorrhagia. ${ }^{6}$

Hysterectomy must never be done without proper indications. According to Dicker, hysterectomy is indicated when the risk of preserving the uterus is greater than the risk of its removal or when medical treatment is not successful in relieving the disabling symptoms. ${ }^{7}$ Hysterectomy should not be done as a prophylaxis against mild abnormal cervical cytology or without a trial of medical treatment in endometrial hyperplasia. ${ }^{8}$

Sometimes there are considerable problems in clinical assessments, as the patients do not understand the severity of their symptoms, as a result the findings often do not co-relate with their complaints and the clinical and per operative diagnosis does not correlate with histopathological diagnosis. Women from rural areas seek medical care late, due to socio-economic factors and availability to health care facilities, when conservative treatment is not possible and the best treatment option will be hysterectomy, but with proper selection of patients the morbidity and mortality of hysterectomy can be kept low. 9,10

Majority of the hysterectomy procedures are performed via an abdominal approach (64\%) -TAH total abdominal hysterectomy and TAH+BSO- total abdominal hysterectomy with bilateral salphingo-oophorectomy, or vaginal route (22\%)- VH+PFR-vaginal hysterectomy with pelvic floor repair, and by laparoscopy (14\%)- TLH -total laparoscopic hysterectomy or LAVH laproscopic assisted vaginal hysterectomy Jacoby et al. ${ }^{1}$ The society of pelvic reconstructive surgeons issued guidance regarding the, hysterectomy route in 1999, since then vaginal hysterectomy has again gained favor. ${ }^{11}$

Abnormal uterine bleeding, myoma uteri and endometrial hyperplasia are the most common indications for hysterectomy; the other indications are adenomyosis and uterine prolapse.

Abnormal uterine bleeding is caused by hormonal imbalance and conditions such as polyps, myomas, endometrial hyperplasia and cancers of the cervix and endometrium. Hyper estrogenic conditions where the endometrium is in the proliferative phase if untreated, may lead to endometrial carcinoma. Bleeding in postmenopausal women is the most common presenting symptom for endometrial cancer. Most common histopathological diagnoses reported in hysterectomy specimens are leiomyoma, adenomyosis and endometrial hyperplasia. $^{12}$
In hysterectomies performed, the clinical and per operative findings often do not correlate with the histopathological diagnosis. This is a retrospective study to correlate and evaluate the sensitivity between the indications, demographic features, and clinical presentations and per-operative findings and histopathological diagnosis in patients who underwent hysterectomy.

\section{METHODS}

This is a retrospective study conducted in the department of Obstetrics and Gynaecology, in SVMCH and RC, Ariyur, Pondicherry, India. There were 1124 cases of hysterectomies done over a period of five years, from 2011 to 2015.

Data was recorded and analyzed from the case record of each patient, which was obtained from the medical record department of the hospital. The age, parity, clinical presentation, clinical findings, along with the ultrasonographic findings were taken into account to establish the clinical diagnosis. The final indication for surgery, type of hysterectomy, and the operative findings of each patient was recorded for analysis. The surgical specimens had been sent to the pathology department where they were fixed in $10 \%$ buffered formalin embedded in, paraffin and 4-5 $\mu \mathrm{m}$ thick sections were cut and stained with haematoxylin and eosin. Special stains were used when required. The histopathological diagnosis and reports were analyzed. Finally the clinical diagnosis was correlated with histopathological findings in the tabulated form for evaluation.

\section{RESULTS}

During the study period there were 1124 cases of hysterectomies done; out of which total abdominal hysterectomy with Bilateralsalphingo -oophorectomy cases were $915(81.4 \%)$. Vaginal hysterectomy with Pelvic floor repair cases were $153(13.6 \%)$ and total abdominal hysterectomy cases were $56(5 \%)$ as shown in Table 1.

Table 1: Distribution of cases by type of hysterectomy done.

\begin{tabular}{|lll|}
\hline Type of hysterectomy & Number of cases & $\%$ \\
\hline VH+PFR & 153 & 13.6 \\
\hline TAH & 56 & 5.0 \\
\hline TAH+BSO & 915 & 81.4 \\
\hline Total & $\mathbf{1 1 2 4}$ & $\mathbf{1 0 0}$ \\
\hline
\end{tabular}

The age incidence of these patients is shown in Table 2. It is in the age group 41 to 50 years that the maximum numbers of hysterectomies were done 776 cases $(69 \%)$ followed by 270 cases (24\%) in age group 31 to 40 years. 
Table 2: Age wise distribution of hysterectomy cases.

\begin{tabular}{|lll|}
\hline A ge in years & Number of cases & $\%$ \\
\hline 31 to 40 & 270 & 24 \\
\hline 41 to 50 & 776 & 69 \\
\hline 51 to 60 & 56 & 5 \\
\hline 61 to 70 & 22 & 2 \\
\hline Total & $\mathbf{1 1 2 4}$ & $\mathbf{1 0 0}$ \\
\hline
\end{tabular}

In the presenting complaints, as shown in Table 3, menorrhagia is dominant 713 cases $(63.4 \%)$, followed by mass descending per vaginum $12.9 \%$, discharge per vaginum $11.6 \%$, pain abdomen $11 \%$ and postmenopausal bleeding in $1.1 \%$.

Table 3: Distribution of cases by the presenting complaints.

\begin{tabular}{|lll|}
\hline Presenting complaints & Number of cases & $\%$ \\
\hline Mass descending per vaginum & 145 & 12.9 \\
\hline Menorrhagia and dysmenorrhea & 713 & 63.4 \\
\hline Pain abdomen & 124 & 11.0 \\
\hline Discharge per vaginum & 130 & 11.6 \\
\hline Post-menopausal bleeding & 12 & 1.1 \\
\hline Total & $\mathbf{1 1 2 4}$ & $\mathbf{1 0 0}$ \\
\hline
\end{tabular}

In the final clinical diagnosis of this study, leiomyoma is the commonest, 324 cases $(28.8 \%)$ followed by abnormal uterine bleeding 298 cases $(26.6 \%)$. The incidence of adenomyosis is $11 \%$ (124 cases) Table 4.

Table 4: Distribution of cases by the clinical diagnosis.

\begin{tabular}{|lll|}
\hline Clinical diagnosis & Number of cases & $\%$ \\
\hline Uterovaginal prolapse & 145 & 12.9 \\
\hline Leiomyoma & 324 & 28.8 \\
\hline Adenomyosis & 124 & 11.0 \\
\hline AUB & 298 & 26.6 \\
\hline Benign ovarian tumor & 102 & 9.1 \\
\hline Chronic cervicitis & 105 & 9.3 \\
\hline CIN & 26 & 2.3 \\
\hline Total & $\mathbf{1 1 2 4}$ & $\mathbf{1 0 0}$ \\
\hline
\end{tabular}

Table 5: Distribution of cases by the histopathological diagnosis.

\begin{tabular}{|lll|}
\hline Histopathological diagnosis & Number of cases & $\%$ \\
\hline Leiomyoma & 252 & 22.4 \\
\hline Adenomyosis & 244 & 21.7 \\
\hline Adenomyosis+leiomyoma & 72 & 6.4 \\
\hline Endometrial hyperplasia & 158 & 14.1 \\
\hline Benign ovarian tumor & 102 & 9.1 \\
\hline CIN 2/3 & 26 & 2.3 \\
\hline Chronic cervicitis & 105 & 9.3 \\
\hline Atropic endometrium & 54 & 4.8 \\
\hline Proliferative endometrium & 111 & 9.9 \\
\hline Total & $\mathbf{1 1 2 4}$ & $\mathbf{1 0 0}$ \\
\hline
\end{tabular}

Leiomyoma is the dominant histopathological diagnosis in our study, 22.4\% (252 cases) followed by adenomyosis $21.7 \%$ (244 cases). Both adenomyosis and leiomyoma was present in 72 specimens $(6.4 \%)$. Chronic cervicitis was seen in $9.3 \%$ of the cases and CIN 3 (cervical intra epithelial neoplasia) in $2.3 \%$ of the cases. Benign ovarian tumor as an indication for hysterectomy is $9.1 \%(102$ cases). The incidence of atrophic endometrium is $4.8 \%$, where as that of disordered proliferative endometrium is 9.9\% (111) cases Table 5.

\section{DISCUSSION}

In our study the maximum incidence of hysterectomy is in the age group of 41 to 50 and the mean age in our study is 44.5 years. Similar incidence is reported by Selvi $\mathrm{T}$ et al and other studies. ${ }^{13-15}$ According to Chryssikopoulos A et al $74.8 \%$ of the patients undergoing abdominal hysterectomy were aged 36 to 55 years, mean 44.2, whereas the patients undergoing vaginal hysterectomy were aged 56 to 75 years mean $44.3 .{ }^{16}$

In the present study, total abdominal hysterectomy with Bilateral salphingo oophorectomy is the commonest, $81.5 \%$. Gyam A has reported a $77.3 \%$ incidence of hysterectomies by abdominal route. ${ }^{17}$ An incidence of $81.7 \%$ is being reported from Gombe, Nigeria. ${ }^{18}$ Our incidence is comparable to similar other studies. ${ }^{9,19}$ The abdominal route for hysterectomy was also the preferred route in a study in Istambul $82.7 \% .^{20}$ In a study by Chryssiopoulos et al, the abdominal route of hysterectomy was $85.33 \%$ and the vaginal route was $14.67 \%$, which is comparable to our study. ${ }^{16}$

The main presenting complaint in our study is menorrhagia $(63.4 \%)$, followed by mass per vaginum $(12.9 \%)$. This is similar to the study of Mahmoud Khaniki et al, where abnormal uterine bleeding was the chief complaint $62.2 \%$, abdominal pain $13.3 \%$ and uterine prolapse $7.4 \% .^{21}$ Shergill SK reported, menorrhagia as the chief complaint in women undergoing hysterectomy $66 \% .^{22}$ The incidence of uterovaginal prolapse in the study of Neena $\mathrm{Y}$ et al is $18 \% .^{23}$ The other cases in our study presented with the complaints of discharge per vaginum (11.6\%), pain abdomen $(11 \%)$ and postmenopausal bleeding $(1.1 \%)$.

Leiomyoma was the main indication for hysterectomy in our study $28.8 \%$, which is similar to the studies of Ajmera et al, Gupta et al, Khan R et al. ${ }^{19,24,25}$

Isaoglu et al reported, leiomyoma as an indication of hysterectomy at $28.19 \%$, whereas Dincgez et al quoted leiomyoma to be the indication for hysterectomy at $32.77 \% .^{12,26}$ Shergill SK reported leiomyoma as the commonest indication for hysterectomy $34 \%$ followed by abnormal uterine bleeding $26 \%$. $^{22}$

Abnormal uterine bleeding (AUB) is the second commonest indication for hysterectomy in our study 
$26.6 \%$, followed by adenomyosis $11 \%$ and chronic cervicitis $9.3 \%$, benign ovarian tumor $9.1 \%$, CIN $32.3 \%$. Similar report is quoted by Cameron IT. ${ }^{27}$ According to the study of Jha et al, leiomyoma is the indication for hysterectomy is $24.9 \%$, benign ovarian tumor is $14.9 \%$ and AUB is $7.7 \% .{ }^{15}$ Whereas Clarke et al reported the commonest indication to be AUB $58 \%$ followed by leiomyoma $23.2 \% .^{28}$ According to Neena et al, adenomyosis is an indication for hysterectomy is $10 \%$ and utero-vaginal prolapse $18 \% .^{23}$ Aksuf et al reported, leiomyoma is the commonest indication for hysterectomy $38.49 \%$ followed by uterine prolapse $11.9 \% .^{20}$ In the study of Tan XJ et al the indications were, leiomyoma $56.2 \%$, adenomyosis $12.2 \%$, benign ovarian tumor $9.2 \%$ and genital prolapse $7.7 \% .^{29}$

In the histopathological diagnosis of our study, leiomyoma is predominant $22.4 \%$ followed by adenomyosis $21.7 \%$. Both leiomyoma and adenomyosis are seen in $6.4 \%$ of the cases. The incidence of leiomyoma is about $20 \%$ in reproductive age group and increases with age, which is similar in our study. ${ }^{30}$ In a study by Sobande AA, leiomyoma was the commonest histopathological diagnosis $25.8 \%$ of the hysterectomy specimens followed by adenomyosis $22.7 \%$. ${ }^{10}$ According to Bhide et al the histopathology incidence of leiomyoma is $19 \% .{ }^{31}$ Similar reports were published by Sarfraz T and Praveen S. ${ }^{32,33}$ Whereas Jamal S, Braai S, reported leiomyoma at $35.7 \%$ and adenomyosis $30 \%$. $^{34}$ Isaoglu reported adenomyosis to be found in $30.23 \%$ of the cases. $^{12}$ According to Abdulla LS leiomyoma is the commonest histopathology followed by adenomyosis. ${ }^{9}$ Leiomyoma and adenomyosis were present together in $6.4 \%$ of our study which is similar to the study of Sarfarz, Sakria and Talukder..$^{32,33,35}$ In our study there were 3 cases of leiomyoma with endometrial hyperplasia.

In our study endometrial hyperplasia is the histopathology diagnosis in $14.1 \%$ of the cases. A similar incidence is reported by Ranabhat et al. ${ }^{36}$ Similar report is also by Isaoglu U. ${ }^{12}$ Whereas Ojeda et al reported endometrial hyperplasia at $22.3 \% .^{37}$

In this study atropic endometrium was the histopatholological diagnosis in $4.8 \%$ and proliferative endometrium in $9.9 \%$ of the cases. Atrophic endometrium was found in utero vaginal prolapse specimens, and proliferative endometrium was the diagnosis in women of more than 45 years of age with abnormal uterine bleeding. Chronic cervicitis was diagnosed in $9.3 \%$ and CIN3 in $2.3 \%$ of the cases. All cases of chronic cervicitis were clinically diagnosed and histologically proven. CIN3 was suggestive by papaincolaou smear stain and proven by histology. Benign ovarian tumor was the diagnosis in $9.1 \%$ of the cases, diagnosed clinically and proven by histology.

In our study the pre-operative diagnosis specificity to pathological correlation is 91 to $100 \%$, leiomyoma $99 \%$, endometrial hyperplasia is $97 \%$, adenomyosis $92 \%$, CIN is $91 \%$, and chronic cervicitis is $99.1 \%$ and benign ovarian tumor $100 \%$. Lee NC in his study had $80 \%$ preoperative diagnosis correlated to histopathology diagnosis, of which endometrial hyperplasia was $95 \%$ and CIN $89 \% .^{38}$

\section{CONCLUSION}

There has been a remarkable improvement in conservative management of uterine lesions; still hysterectomy is the preferred procedure in the treatment for pelvic pathologies like leiomyoma, adenomyosis, pelvic inflammatory disease, malignant disorders, and genital prolapse. Majority of the hysterectomy procedures are performed via an abdominal approach. Reconstructive Surgeons issued guidance regarding the, hysterectomy route in 1999, since then vaginal hysterectomy has again gained favour. The maximum incidence of hysterectomy is in the age group of 41 to 50. Leiomyoma was the main indication for hysterectomy. In the histopathological diagnosis, leiomyoma is predominant followed by adenomyosis. The pre-operative diagnosis specificity to pathological correlation in leiomyoma is $99 \%$.

Funding: No funding sources

Conflict of interest: None declared

Ethical approval: The study was approved by the Institutional Ethics Committee

\section{REFERENCES}

1. Maresh MJ, Metcalfe MA, McPherson K, Overton C, Hall V, Hargreaves J, et al. The VALUE national hysterectomy study: description of the patients and their surgery. BJOG. 2002;109:302-12.

2. Rather GR, Gupta Y, Bharadwaj S. Patterns of lesions in hysterectomy specimens; a prospective study. J K Science. 2013;15(2)63-8.

3. Singh A, Arora AK. Why hysterectomy rate are lower in India. Indian $\mathbf{J}$ Community Med. 2008;33(3):196-7.

4. John A, Rock MD, Jhon D, Thompson MD. Telinds's operative gynaecology. $1^{\text {st }}$ Edition Lippincott. Med J; 2003:878-890.

5. Nousheen F, Iqbal J, Bhatti FA, Sheik S. Hysterectomy the patient perspective. Ann Gynaecol. 2004; 10:339-41.

6. Olsson JH, Ellstrom M, Hahlin M. A randomized prospective trial comparing laparoscopic and abdominal hysterectomy. British Journal of Obstetrics and Gynaecology. 1996;103:345-50.

7. Dicker RC, Seally MJ, Greenspan JR, Layde PM, Ory HW, Maze JM, et al. Hysterectomy among women of reproductive age trends in United States. JAMA. 1990;248:328-35.

8. Wood C, Maher P, Hill D, Selwood T. Hysterectomy: a time of change. Med J Aust. 1992;157:651-3. 
9. Abdulla LS. Hysterectomy: a clinic pathological correlation, Bahrain Medical Bulletin. 2006;28(2):16.

10. Sobande AA, Eskander M, Archibong EI, Damole IO. Elective hysterectomy: a clinic pathological review from Abha catchment area of Saudi Arabia. West Afr J Med. 2005;24:31-5.

11. Jacoby VL1, Autry A, Jacobson G, Domush R, Nakagawa S, Jacoby A. Nationwide use of laparoscopic hysterectomy compared with abdominal and vaginal approaches. Obstet Gynecol. 2009:114:1041-8.

12. Isaoğlu $U$. The evaluation of diagnosis in specimens of hysterectomy. Abant Med J. 2013;2(2):941-943.

13. Ramachandran TS, Sinha R, Subramanium. Correlation between clinic pathological and ultrasonographic findings. Journal of Clinical Diagnosis and Research. 2011;5(4):734-40.

14. Huma Z, Naeem A, Shoaib M, Fayyaz S, Arjumand. A clinic pathological review of elective hysterectomies in Sir Ganga Ram hospital. Pak J Med Health Sci. 2012;6(4):970-2.

15. Jha R, Pant AD, Jha A, Adhikari RC, Syami G. The histopathological analysis of hysterectomy specimens. J Nepal Med Assoc. 2006;45(163):28390.

16. Chryssipolous A, Loghi SC. Indications and results of total hysterectomy. Int Surg. 1986;71(3):188-94.

17. Gaym A. Elective hysterectomy at Tikur Anbessa teaching hospital, Addis Ababa. Ethiop Med J. 2002;40(3):217-26

18. Bukar M, Audu B, Yahaya UR. Hysterectomy for benign gynaecological conditions at Gombe, North Eastern Nigerian. Nig Med J. 2010;35-8.

19. Ajmera SK, Mettler L, Jonat W. Operative spectrum of hysterectomy in a German university hospital. J Obstet Gynecol India. 2006;56(1):59-63.

20. Aksu F, Gezerand A, Oral E. Seventeen-year review of hysterectomy procedures in a university clinic in Istanbul (1985-2001). Archives of Gynecology and Obstetrics. 2004;(4):217-22.

21. Khaniki M, Shojaie M, Tarafdari AM. Histopathological study of hysterectomy operations in a University clinic in Tehran from 2005 to 2009. J Fam Reprod Health. 2011;5(2):51-5.

22. Shergill SK, Shergill HK, Gupta M, Kaur S. A clinic pathological study on hysterectomies. J Indian Med Assoc. 2002;100(4):238-9.

23. Neena Y, Honey B. Clinico-pathological correlation of hysterectomy specimens for abnormal uterine bleeding in rural area. J Evol Med Dent Sci. 2013;39(2):7506-12.

24. Gupta G, Kotasthane DS, Kotasthane VD. Hysterectomy: a clinico-pathological correlation of
500 cases. The Internet Journal of Gynaecology and Obstetrics. 2010;14(1):1-5.

25. Khan R, Sultana H. How does histopathology correlate with clinical and operative findings in abdominal hysterectomy? JAFMC Bangladesh. 2010;6(2):17-20.

26. Dinçgez B, Coşkun EI, Ayanoğlu YT. Kliniğimizdegerçekleştirilen histerektomi olgularının değerlendirilmesi. Şişli Etfal Hastanesi Tıp Bülteni. 2011;45:35-8.

27. Cameron IT. Laparoscopy and laparoscopic surgical techniques in Whitfield CR, ed. Drewhurst Textbook Obstetrics and Gynaecology for Postgraduate Students, $6^{\text {th }}$ edn. London: Blackwell Scientific Publication; 1999:505-22.

28. Clarke A, Black N, Rowe P, Mott S, Howle K. Indications for and the outcome of total abdominal hysterectomy for benign disease: prospective cohort study. Br J Obstet Gynaecol. 1995;102:611-20.

29. Tan XJ, Lang JH, Shen K, Liu ZF, Sun DW, Leng $\mathrm{JH}$, et al. Operative approaches, indications, and medical economics evaluation of4180 cases of hysterectomy. Zhongguo Yi Xue Ke Xue Yuan Xue Bao. 2003;25(4):406-9.

30. Jeffcoate's Principles of Gynaecology $7^{\text {th }}$ international edition Kumar P, Narendra Malhotra; 2014:490.

31. Bide P, Bhide A. Uterine adenomyosis. J Obstet Gynecol. 1994;44(4):612-5.

32. Sarfraz T, Tariq H. Histopathological findings in menorrhagia: a study of 100 hysterectomy Specimens. Pak J Pathol. 2005;16(3):83-5.

33. Praveen S, Tayyab SH. Clinic pathological review of elective abdominal hysterectomy. Journal of Surgery Pakistan. 2008;13(1):26-9.

34. Jamal S, Braai S. A clinic histopathological analysis of 260 Hysterectomies Pakistan. J Pathol. 2001;12(2):11-4.

35. Talukder SI, Haque MA, Huq MH, Alam MO, Roushan A, Noor Z, et al. Histopathological analysis of hysterectomy specimens. Mymensingh Med J. 2007;16(1):81-4.

36. Ranabhat SK, Shrestha R, Tiwari M, Sinha DP, Subedee LR. A retrospective histopathological study of hysterectomy with or without salpingooophorectomy specimens. JCMC. 2010;1(1):26-9.

37. Ojeda VJ. The pathology of hysterectomy specimens. Z Med J. 1979;89:169-71.

38. Lee NC, Dicker RC, Rubin G, Oray HW. Confirmation of the preoperative diagnosis for hysterectomy. Am J Obstet Gynecol. 1984;150(3):283-7.

Cite this article as: Neelgund $\mathrm{S}$, Hiremath $\mathrm{P}$. Analytical study of hysterectomies. Int J Reprod Contracept Obstet Gynecol 2016;5:2307-11. 